Lamar State College of Technology Research Series

$$
\text { Paper No. } 7
$$

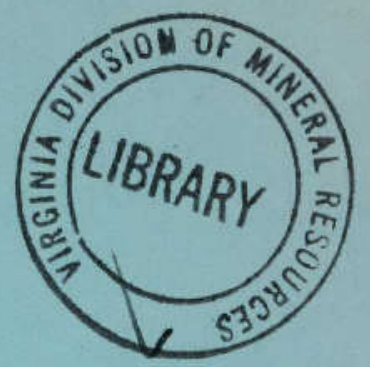

\title{
Surface Tension of Acetone-water Solutions \\ Up to their Normal Boiling Points
}

\author{
Katherine Howard and R. A. McAllister
}

Reprinted from A. I. Ch. E. Journal, September 1957

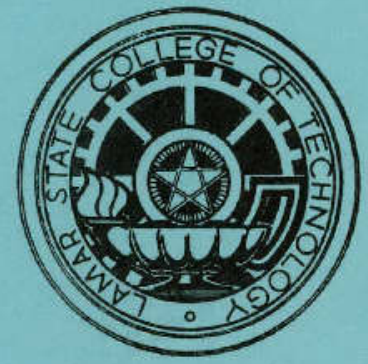

Lamar State College of Technology

Beaumont, Texas 

The surface tensions against air of acetone-water solutions have been measured over the entire composition range from $20^{\circ} \mathrm{C}$. to generally within $1^{\circ}$ to $10^{\circ} \mathrm{C}$. of the normal boiling points. The capillary-height method was employed and the results are thought to be accurate to better than $\pm 0.5 \%$.

Thysical-property data for binary liquid systems up to the boiling points of the solutions are scarce, and the present status of the kinetic theory of liquids is not sufficiently developed to enable accurate predietions to be made over the entire composition and temperature range, One of the aims of Research Project 1, Tray Efficiencies in Distillation Columns, sponsored by the American Institute of Chemical Engineers, has been to detcrmine the effect of the physical properties of the system on the distillation efficiency. The role of the boiling-point surface tension in relation to distillation efficiency, for example, is not well defined. As this lack of understaslding can be attributed in part to the scareity of surfuce-tension data at the boiling temperatures, one of the purposes of this investigation was to provide accurate surface-tension data up to the boiling point for use in distillationefficiency correlations.

Morgan ard Scarlett ( 8 ) have measured the surface tension of acetone-water solutions at $0^{\circ}, 25^{\circ}$, and $45^{\circ} \mathrm{C}$. using the drop-weight method. Traube (19) reported surface-tension measurements "for acetone-water solutions (up to 2.0 mole \%) at $15^{\circ} \mathrm{C}$. as measured by the capillaryheight method. All these data have been tabulated ${ }^{*}$ and will be compared with

* Tabular material has been cleposited as document 5309 with the Aprerican Dopumentration Tnstitute, Photoduplication Service, Library of for $\$ 1.25$ for photoprints or 35 -mm. mierofilm.

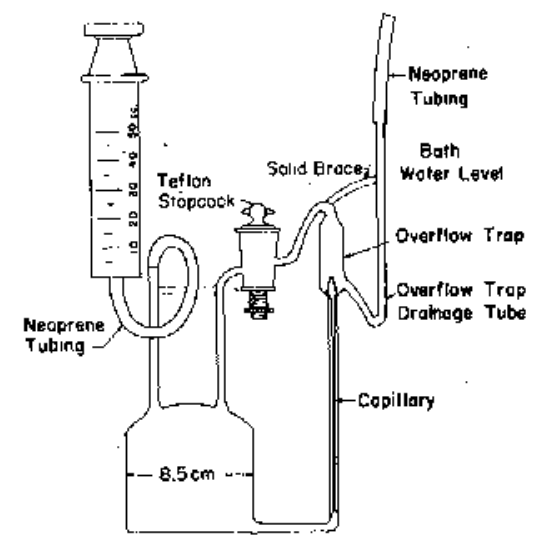

Fig. 1. Diagram of surface-tension apparatus. the present work in the discussion of results below. Using only the data in the literature up to $45^{\circ} \mathrm{C}$. would necessitate extrapolations from $11^{\circ}$ to $55^{\circ}$. to get the boiling-point surface tensions over the "entire composition range. The accuracy of such an extrapolation would be doubtful, especially since the accuracy of the data themselves has not been confirmed.

\section{EQUIPMENT AND PROCEDURE}

\section{Apparatus}

Surface-tension Apparatizs. The apparatus used for the capillary-height measurement was a modification of the design suggested by Richards and Carver (10), incorporating the overflow trap used by Young, Gross, and Harkins (2). The apparatus, shown in figure 1 , was constructed of Pyrex and was equipped with a Tefton stopcock. The capillary tube was selected from precision-bore Pyrex capillary tubing, rated as $0.25 \pm 0.01 \mathrm{~mm}$. I.D. In the selection of the capillary tube, its diameter was checked by the method doscribed by Harking (3), which involved filling the entire tube with a woighed volume of pure mercury and measuring. its length to determine the average radius. The length of a short, weighed bead of mereury, plsced at overlapping positions along the capillary, was repeatedly measured to determine any variation in radius caused by nonuniformity of the capillary bore. With this method, a $17-\mathrm{cm}$. capillary tube was selected having an average radius of $0.01338 \mathrm{~cm}$, a maximum deviation of $\pm 0.4 \%$, and an average deviation of $\pm 0.2 \%$. An $8-\mathrm{cm}$. section near the center of this capillary had an average radius of $0.01340 \mathrm{~cm}$. with a maximum deviation of $\pm 0.15 \%$ and an average' deviation of $\pm 0.02 \%$. The capillary was oriented in the apparatus so that this extremely uniform section might be used for all experimental work. After the construction of the apparatus the capillary was recalibrated, as described below, and the radius was found to have changed, probably in the annealing process.

The diameter of the large tube was of sufficient sizc $(8.5 \mathrm{~cm}$ ) to avoid any curvature of the large meniscus.

To the large tube-side arm was attached a 50-ml. hypodermic syringe (Becton, Dickinson and $\mathrm{Co}$.) in order to apply slight pressure for rinising the capillary tube. The syringe conneetion was made with ncoprene tubing which had been washed well with water and acetone. The capillary-tube-side arm was closed with a similar neoprene tube, equipped with a scrow clamp.

Support and Lighting. For suspension in the water bath, the glass apparatus was mounted with thermometcr clamps on a support constructed of $1 / 4-\mathrm{in}$, iron. This support had an adjustable slit (13 $\mathrm{cm}$. long; $0-1.5 \mathrm{~cm}$. widle) located just behind the large tube of the surface-tension apparatus. For effective illumination of the large meniscus, a box containing a fluorescent lamp (GIS 2A) and equipped with an adjustable slit identical to that of the support was placed behind the apparatus. The light source was mounted with a rack and pinion used for leveling the light slit with the support slit. This lighting method greatly facilitated accurate determination of the position of the large meniscus.

The capillary meniscus was illuminated by a standard adjustable-height microscope lamp (American Optical Co.).

Temperature Control. Accurate temperature control $\left( \pm 0.02^{\circ} \mathrm{C}\right.$. $)$ in a 12-gal. water bath was provided by a tungsten-mercury thermoregulator (Fisher Scientific Co. 15180-5) attached to a combination heator and circulating pump (E. H. Sargent and Co.). Cooling was provided by a seven-coil copper tube attached to a refrigerated water-methanol line. The temperature was measured by a thermometer which was graduated to $0.1^{\circ} \mathrm{C}$. and which had been calibrated by the Nationa] Bureau of Standards.

Height Measurements. The large meniscus and the capillary meniscus heights were rneasured with eathetometcrs. During the eurly portion of the work a $40-\mathrm{cm}$, cathetometer, calibrated to $0.01 \mathrm{~cm}$. (Eberbach and Son Co., Inc.) was ured; later a 100-cm. cathetometer calibrated to 0.005 mm. (Fisher Scientific Co.) became available.

\section{Solvents}

Water. The water used both for calibration purposes and for preparation of acetone-water solutions was daily prepared from once-distilled water (Barnstead still) by redistillation in an all-quartz still, the middle cut (one-third the starting volume) being retained. Such water had a specific conductance of $1 \times 10^{-6}$ reciprocal ohms and a refractive index, $n_{D}{ }^{25}$, of 1.33250 , and will be referred to as conductivity water.

Acetone. The acetone (Baker analyzed, $99.6 \%$ acetone) was analyzed by refractive index and its density was determined (11). From these data it was posible to prepare a refractive index vs. concentration curve for 98.0 to 100.0 mole $\%$ acetone for aceurate determination of the water content (11). This analysis indicated that the actual composition of the starting material was 99.54 mole \% acctone, 0.45 mole \% water. Distillation of the material in a fractional distillation column packed with 1/8-in. I.D. 
TABI:E 1

Surface Tension of Water used in THE CALIBRation

$\begin{array}{cc}\begin{array}{c}\text { Temperature, } \\ { }^{\circ} \mathrm{C} .\end{array} & \begin{array}{c}\text { Surface tension," } \\ \text { dynes/cm. }\end{array} \\ 15.00 & 73.531 \\ 20.00 & 72.800 \dagger \\ 25.00 & 72.018 \\ 30.00 & 71.231 \\ 37.78 & 69.980 \\ 45.00 & 68.790 \\ 50.05 & 67.939 \\ 60.11 & 66.207 \\ 70.20 & 64.401\end{array}$

*With the exception of $20^{\circ} \mathrm{C}$., the surface-tension values were calculated by use of the formulas (E)

$\sigma=75.796-0.145 t-0.00024 t^{2}\left(10^{\circ}\right.$ to $60^{\circ} \mathrm{C}$. $)$ (2)

$\sigma=75.680-0.138 t-0.000356 t^{2}+0.00000047 t^{8}$

where $t$ is in degreen centigrade.

The yalues calculated by the two formulas agree very closely, and the average of the two values is given in the table.

$\dagger$ Reported by Harkins and Brown (6).

TABLE 2

Surface Tengion and Dengtty of BenZeNe Used in THE CALTBHation

$\begin{array}{ccc}\text { Temperature, } & \begin{array}{c}\text { Surface } \\ \text { tension, } \\ \text { dynes/cm. }\end{array} & \begin{array}{c}\text { Denzity, } \\ \text { g. } / \text { cc. }\end{array} \\ 20.00 & 28.858 \ddagger & 0.87896 \\ 30.00 & 27.560 \ddagger & 0.86840 \\ 50.05 & 24.950 & 0.8467 \\ 60.11 & 23.658 & 0.8358\end{array}$

*Calculated from the formula (6a)

$$
\sigma=31.556-0.135 t+0.00000 t^{2}
$$

†Averages of valued oompiled by Timmermans $\left(18, p_{1}, 145\right)$.

T W $20^{\circ} \mathrm{C}$ the sccepted value (b), (g), [Richards, 1856 1915 . B. Coombs, J. Am. Chem. Soc., 37, at $30^{\circ} \mathrm{C}$. Harkins W. D. and $Y$. C. Cheng, 260 . 43,35 (1921) If theae value are und the calcilated radius from the benzene calibration is 0.01332 cII. $\pm 0.2 \%$.

Pyrex helices (packing $1 \times 90 \mathrm{~cm}$.) showed a boiling range of 56.1 to $56.2^{\circ} \mathrm{C}$. (749 to $750 \mathrm{~mm}$.).

Benzene. The benzene used for calibration purposes was prepared from starting material containing less than $0.02 \%$ water (Baker analyzed) having a refractive index $\left(n_{D}{ }^{23}\right)$ of 1.49762. Fractional crystallization was carried out three times, each time one-half the volume being allowed to freeze and this frozen portion retained. The refractive index increased to the value $n_{D}{ }^{25}=1.49798$ after the second crystallization and was unchanged by further crystallizations. The average of nine determinations reported by Timmermans (12) for $100 \%$ benzere is $n_{D}{ }^{25}=1.49800$. Analysis of this purified material for water by Karl-Fischer titration indicated a water content of $0.0146 \%$ by weight. This amount of water is probably jntroduced through handling and transferring of the ample for titration.

\section{Calibration}

Water. The apparutus was calibrated with water at $15^{\circ}, 20^{\circ}, 25^{\circ}, 30^{\circ}, 37.78^{\circ}\left(100^{\circ} \mathrm{F}\right.$.), $50^{\circ}, 60^{\circ}$, and $70^{\circ} \mathrm{C}$. Conductivity water was distilled directly into the apparatus and its capillary rise was measured after a 45 - to 60 - $\mathrm{min}$, temperature-equilibration period, (Details of the procedure involved
TABLE 3

Surfacin Tangion and Ligutd and Vapor Dengities of the Acetone-water Sygtem

$\begin{array}{cccc}\begin{array}{c}\text { Mole \% acetone } \\ 15.00^{\circ} \mathrm{C} .\end{array} & \begin{array}{c}\text { Liquid density, } \\ \text { g./cc. }\end{array} & \begin{array}{c}\text { Vapor density, } \\ \text { g. } / \text { cc. } \times 10^{3}\end{array} & \begin{array}{c}\text { Surface tension, } \\ \text { dynes/cm. }\end{array} \\ 0 & 0.9990995 & 1.203 & 73.39 \\ 0.125 & 0.99865 & 1.205 & 70.00 \\ 0.29 & 0.99805 & 1.21 & 67.00 \\ 0.60 & 0.9969 & 1.2 & 62.99 \\ 1.44 & 0.9938 & 1.2 & 57.33 \\ 2.03 & 0.99155 & 1.24 & 54.62\end{array}$

$20.00^{\circ} \mathrm{C}$.

0

$0.9982053 \ddagger$

$2.96 \quad 0.9868$

5.63

0.9775

8.86

14.59

0.9665

0.9479

19.02

24.95

30.1

46.1

0.9338

0.9166

0.9034

0.8654

53.4

60.8

69.8

77.5

0.8515

0.8388

0.8252

0.8150

0.8007

0.7912

1.19

1. 26

1.30

1. 34

1.37

1.38

1. 39

1.40

1. 41

1. 41

1,41

1.42

1.43

1.46

1.49

72.74

50.80

41.14

39.40

34.62

32.52

30.49

29.40

27.43

26.77

26.20

25.59

25.09

24.17

23.47

(100)

$(23.24)^{* *}$

$25.00^{\circ} \mathrm{C}$.

0

5.80

14.59

24.95

47.0

67.7

89.2

98.6

(100)

0.9970470

1.17

1.30

0.9745

0.9118

0.8587

0.8232

0.7955

0.7857

1.39

1. 39

1. 41

1.45

1.49 .

1. 53

71.94

42,64

33.56

29.70

26.57

24.96

23.42

22.69

$(22.57)^{* *}$

$37.78^{\circ} \mathrm{C}$.

0

0.11

$0.9930473 f$

0.34

0.71

1.225

1.54

0.9914

0.9897

0.9874

2.08

0.98595

0.98355

0.9797

5.86

0.9676

0.9344

0.8997

25 . 13

0.8449

0.8084

68.3

0.7819

0.7713

1.11

69.91

66.69

62.90

58.80

55.04

53.14

50.54

47.50

40.29

31.78

27.96

24.99

23.25

21.79

21.07

98.3

(100)

1.60

$(20.88)^{* *}$

$50.05^{\circ} \mathrm{C}$.

0

0.11

0.31

0.635

1.13

1.43

2.00

2.89

7.48

14.20

24.83

35.0

46.2

60.9

77.7

90.2

99.5

(100)
$-0.98802 \ddagger$

0.9875

0.9864

0.98475

0.9823

0.9808

0.9780

0.9738

0.9532

0.9260

0.8890

0.8600

0.83345

0.8068

0.7805

0.7645

0.7555
1.02

1.04

1.1

1.08

1.1

1.2

1.2

1.23

1.41

1. 56

1.63

1.66

1.68

1.71

1.77

1.85

1.96
68.05

64.98

61.73

57.81

53.58

51.81 ,

48.96

45.81

36.13

30.24

26.64

25.01

23.93

22.71

21.36

20.41

19.60

$(19.57)^{* *}$ 
TABLE 3-(Continued)

Surface Tension and Liquid and Vapor Densities of the Acetone-water System

$\begin{array}{clcc}\text { Mole } \% \text { acetone } & \begin{array}{c}\text { Liquid density,* } \\ \text { g./cc. }\end{array} & \begin{array}{c}\text { Vapor density, } \dagger \\ \text { g./cc. } \times 10^{3}\end{array} & \begin{array}{r}\text { Surface tens } \\ \text { dynes/cm }\end{array} \\ 60.11^{\circ} \mathrm{C} . & \begin{array}{c}0.98315 \ddagger \\ 0\end{array} & 0.98 & 66.23 \\ 2.90 & 0.9677 & 1.26 & 44.44 \\ 2.90 & 0.9677 & 1.26 & 44.63 \\ 5.69 & 0.9540 & 1.44 & 37.45 \\ 11.07 & 0.9310 & 1.65 & 30.93 \\ 18.35 & 0.9022 & 1.78 & 27.41 \\ 29.4 & 0.86515 & 1.84 & 24.83 \\ 30.4 & 0.86245 & 1.84 & 24.63 \\ 70.20^{\circ} \mathrm{C} & & & \\ 0 & 0.97766 \ddagger & 0.91 & 64.20 \\ 0.11 & 0.9771 & 0.9 & 61.83 \\ 0.325 & 0.9757 & 0.95 & 58.59 \\ 0.60 & 0.97395 & 0.99 & 55.39 \\ 1.08 & 0.9709 & 1.05 & 51.21 \\ 1.11 & 0.97075 & 1.05 & 51.19 \\ 1.45 & 0.96865 & 1.09 & 48.81 \\ 1.63 & 0.96755 & 1.11 & 47.77 \\ 1.87 & 0.9661 & 1.1 & 46.43 \\ 1.94 & 0.9657 & 1.1 & 46.42 \\ 2.77 & 0.9615 & 1.23 & 43.51 \\ 5.42 & 0.9486 & 1.46 & 36.77\end{array}$

*Thomas (11)

tCalculated from the activity coefficients of Brunjes and Bogart $(1)$ and the vapor pressures of water $(\theta, \mathrm{p}, 149)$ and acetone $(9, \mathrm{p}, 153)$, on the assumption that the activity coefficients are independent of temperature, that no association occurs in the vapor phase, and that the perfect-gas law holds.

\pm Perry $(g)$

**Erry (g) iated.

Fig. 2. Surface tension of acetonewater mixtures.

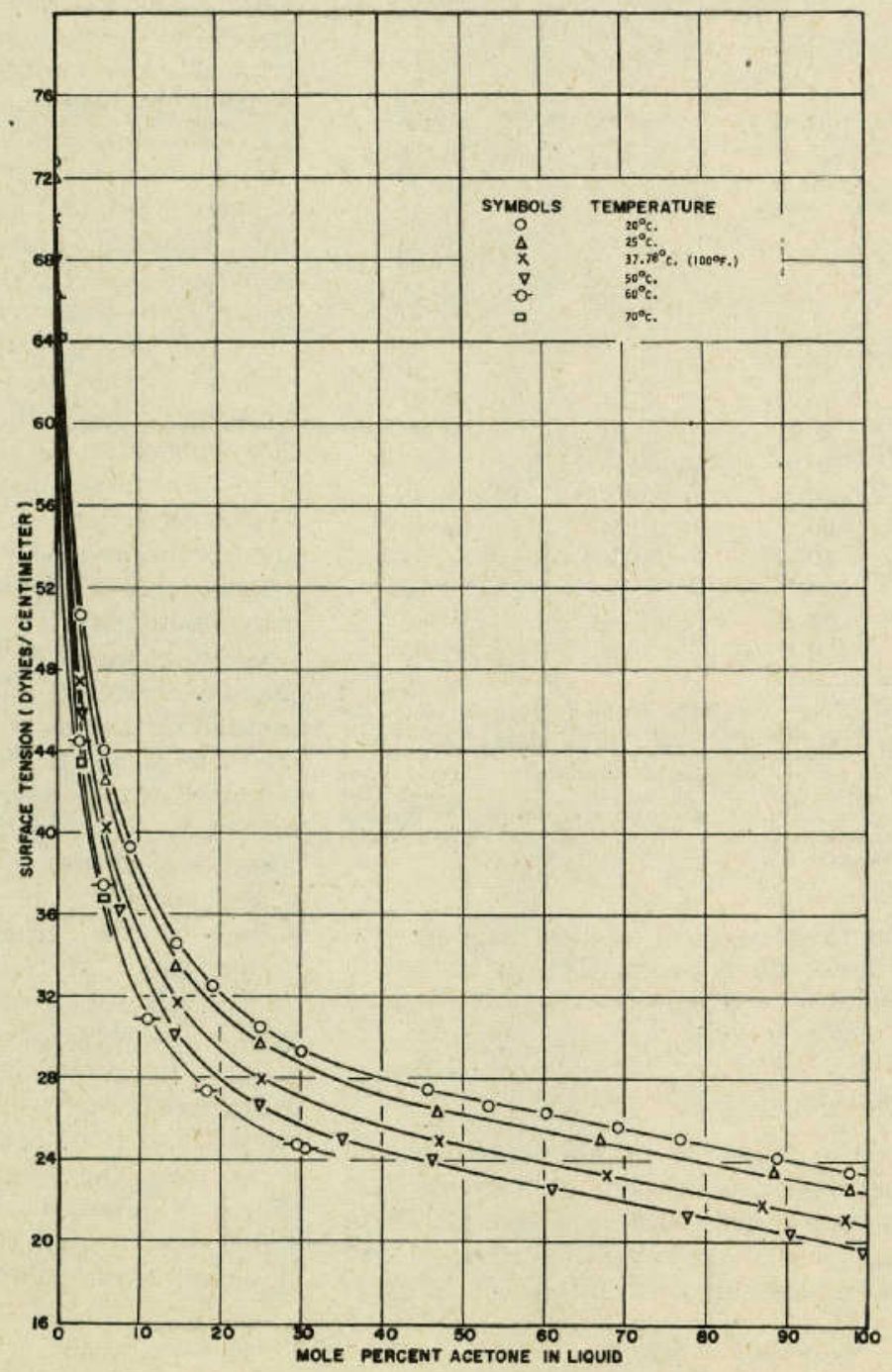

in this measurement are given below.) A minimum of three and a maximum of six determinations were carried out at each temperature. From these capillary-height measurements, the radius of the capillary was calculated by use of the formula

$$
\sigma=\frac{1}{2} \operatorname{rgh}\left(\rho_{L}-\rho_{v}\right)
$$

where

$\sigma=$ surface tension, dynes/cm.

$r=$ capillary radius, $\mathrm{cm}$.

$h=$ capillary height, $\mathrm{cm}$.

$g=$ acceleration due to gravity (979.771 cm. $/$ sec. $^{2}$ here)

$\rho_{L}=$ density of the liquid, g./cc.

$\rho_{v}=$ density of the vapor, g./cc.

The density of water at each temperature required is that reported by Perry (9); the vapor densities were calculated, from the vapor pressures listed by the same author; and the values used for the surface tension of water are given in Table 1 . The average radius from this calibration was found to be $0.01332 \mathrm{~cm}$. $\pm 0.10 \%$, which is equivalent to a reproducibility of $\pm 0.01 \mathrm{~cm}$. in the capillary-height measurement. This radius was used in all surface-tension calculations.

Benzene. A calibration similar to the one reported with conductivity water was carried out with purified benzene at $20^{\circ}$, $30^{\circ}, 50^{\circ}$, and $60^{\circ} \mathrm{C}$. The values used for the surface tension and density of benzene are given in Table 2. The average radius from this calibration was found to be 0.01331 $\mathrm{cm} . \pm 0.2 \%$ and, within experimental error, checked the value obtained from the calibration with water, although the precision was not so good.

Mercury. The average radius was checked by filling the capillary with a weighed sample of pure mercury and measuring its length. The average radius found by this method was $0.01330 \mathrm{~cm}$., and, within experimental error, checked the value found when water and benzene were used for calibration.

\section{Experimental Procedure}

Acetone-water solutions were prepared daily from measured volumes of acetone and conductivity water. Their exact concentrations were determined by refractive index.

The procedure for determination of the capillary height was as follows: the sample (about $80 \mathrm{ml}$.) was introduced through the side arm of the large tube, with the apparatus in place on its support. The $50-\mathrm{ml}$. syringe was attached, with the plunger about halfway up and the apparatus was submerged in the constant-temperature bath, with the capillary exactly vertical. The Teflon stopcock, which had been lubricated with a minimum amount of silicone stopcock grease (Dow Corning), was closed and slight syringe pressure was applied to flush the capillary and to allow a solvent lock to form in the overflow-trap drainage tube. The stopcock was then opened to release pressure, the capillary side arm was closed, and the apparatus was allowed to stand 45 to $60 \mathrm{~min}$. for temperature equilibration. At the end of this period the eapillary side arm was opened for the remainder of the run, but a liquid lock was maintained in the overflow drainage tube. (Investigation showed that 


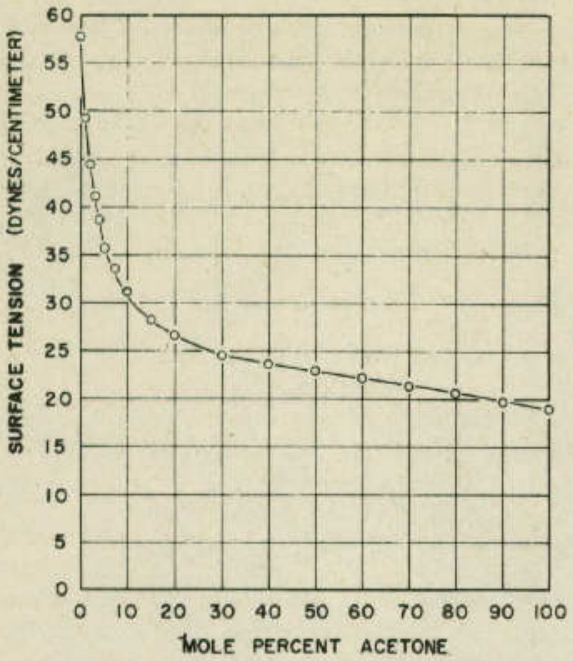

Fig. 3. Surface tension of acetone-water solutions at their normal boiling points.

no measurable difference in capillary height existed between runs, whether the side arm was open or closed, so long as there was no pressure differential between the large meniscus and the eapillary meniscus.) The capillary was flushed in the same manner as before to ensure a fresh capillary surface, a minimum of 15 to $20 \mathrm{~min}$. being allowed for the capillary meniscus to fall to rest. The time required for this stabilization was extensively investigated, water, benzene, and acetone-water solutions being used. The meniscus height was found to remain stationary, after a $10-\mathrm{min}$. stabilization period, for at least $24 \mathrm{hr}$.

After the stabilization period the positions of the large meniscus and the capillary meniscus were recorded at $10-$ min. intervals until triplicate identical readings had been obtained. The capillary was then reflushed to obtain a fresh surface and the whole reading procedure was repeated, usually twice. The agreement in capillary height found by three such successive observations (flushing the capillary between each run) was always within $\pm 0.01 \mathrm{~cm}$. and the differences were rarely greater than \pm 0.005 $\mathrm{cm}$. At the completion of the set of runs samples were withdrawn from the large tube for analysis by refractive index. Comparison of the solution analysis before and after such a set of runs showed very little $(<0.1 \%)$, if any, change in concentration.

With acetone-water solutions at $60^{\circ}$ and $70^{\circ} \mathrm{C}$., it was important to flush the capillary with at least $2 \mathrm{cc}$. of solution in order to obtain reproducible and constant results. Incomplete rinsing resulted in a steadily increasing capillary height at these higher temperatures.

Cleaning. Great care was exercised to provide a scrupulously clean glass surface within the apparatus. The standard cleaning procedure used here involved soaking overnight in chromic acid (concentrated sulfuric acid saturated with potassium dichromate), rinsing eight times with conductivity water, soaking overnight in conductivity water to remove adsorbed chromic acid, and drying in an air oven at $105^{\circ} \mathrm{C}$. Prior to the acid treatment the area exposed to stopcock grease was scrubbed with an alkaline detergent solution. This cleaning procedure was carried out at least once a week; between these cleanings the apparatus was rinsed well with conductivity water and dried at $105^{\circ} \mathrm{C}$.

\section{Analytical Procedure}

All analyses were made by determining the refractive index of the solution and reading the acetone concentration from a standard curve of refractive index vs. mole percentage of acetone. The standard curve was prepared by determining the refractive indexes of solutions which had been prepared by mixing weighed samples of acetone and conductivity water. All weights used in calculating the compositions of the solutions were the corrected vacuum weights. The chain, the rider, and the brass weights used in the analytical balance were checked against National Bureau of Standards calibrated weights, and corrections were noted.

The curve* for refractive index vs, acetone concentration has a maximum at

TABLE 4

Surface Tensions of Acetone-Water Solutions at Their Normal BoILing PoINTS

$\begin{array}{ccc}\begin{array}{c}\text { Mole \% } \\ \text { acetone }\end{array} & \begin{array}{c}\text { Boiling point, } \\ { }^{\circ} \text { C. }^{*}\end{array} & \begin{array}{c}\text { Surface } \\ \text { tension, } \\ \text { dynes/cm. }\end{array} \\ 0 & 100.00 & 57.85 \\ 0.2 & 98.53 & 56.02 \\ 0.4 & 97.10 & 53.77 \\ 0.6 & 95.70 & 51.84 \\ 0.8 & 94.33 & 50.08 \\ 1.0 & 92.99 & 48.83 \\ 1.2 & 91.64 & 47.71 \\ 1.4 & 90.30 & 46.39 \\ 1.6 & 89.00 & 45.58 \\ 1.8 & 87.74 & 44.74 \\ 2.0 & 86.50 & 43.97 \\ 3.0 & 81.32 & 41.37 \\ 4.0 & 77.60 & 39.28 \\ 5.0 & 75.00 & 37.13 \\ 7.5 & 70.20 & 33.60 \\ 10.0 & 66.72 & 30.03 \\ 15.0 & 63.4 & 28.39 \\ 20.0 & 62.2 & 26.61 \\ 30.0 & 61.0 & 24.62 \\ 40.0 & 60.4 & 23.62 \\ 50.0 & 59.8 & 22.98 \\ 60.0 & 59.3 & 22.23 \\ 70.0 & 58.8 & 21.46 \\ 80.0 & 58.2 & 20.67 \\ 90.0 & 57.4 & 19.89 \\ 100.0 & 56.2 & 18.98\end{array}$

*These temperatures were obtained from the data of Brunjes and Bogart (1), D, F. Othmer and R. F. Benenati [Ind. Eng. Chem., 37. 299 (1945)] and J. C. Chu ["Distillation Equilibrium Data," Reinhold Publishing Corporation, New York (1950), p. 24]. More weight was given to the data of Brunjes sistency.

40 to 42 mole \% acetone, and for this reason refractive index alone is not a suitable analysis in the region of 35 to 45 mo'e \% acetone.

\section{RESULTS}

The measured surface tension of the acetone-water system at various temperatures is shown in Table 3 . These values were calculated from the capillaryheight measurements by use of formula 1 .

*See footnote on page 325 .
The vapor and liquid densities of each solution are also given. The surfacetension results are shown graphically in Figure 2.

From the data of Table 3 the surfacetension-vs.-temperature curve was prepared and extrapolated to the normal boiling point. In no case was the extrapolation range greater than $23^{\circ} \mathrm{C}$; ; averaged $8^{\circ} \mathrm{C}$. Table 4 gives the surfacetension values at the normal boiling point, together with the boiling temperatures. The boiling-point surface tensions are shown in Figure 3.

\section{DISCUSSION}

The surface tensions of acetone-water solutions reported here have been compared* with those determined by Morgan and Scarlett (8). The comparison indicates that Morgan and Scarlett's data average $1.5 \%$ higher than those of the authors. The " $100 \%$ " acetone which they used was characterized as $d_{4}{ }^{20}=$ 0.79170 . By the method deseribed by Thomas (11), this density corresponds to 98.16 mole \% acetone, on the assumption that the only contaminant in the sample was water. On this basis Morgan and Scarlett's weight percentage figures were converted to mole percentage and a correction was made for the water content of the acetone used. In addition, erroneous assumptions regarding the relationship between the observed and the ideal drop weights were made by Morgan and Scarlett in the ealculation of surface tension from the experimental data. Young and Harkins (14) attempted to correet these errors in 1928 , but since no accurate measurements of the densities of acetone-water mixtures were available, these recalculations are not currently valid. With regard for all these factors, the data of Morgan and Scarlett were recalculated by use of the dropweight corrections of Young and Harkins and recent accurate determinations by Thomas (11) of the densities of acetonewater solutions.

As an example of other errors which might be involved, Morgan and Scarlett suspended the drops for $5 \mathrm{~min}$. before allowing them to fall. Harkins later indicated (7), however, that it is often necessary to lengthen the time of suspension of drops of volatile liquids where one component adsorbs preferentially in the surface. In the case of acetone-water, if the drop falls before surface adsorption of acetone is at its equilibrium value, there will be excess water in the surface layer and the resulting surface tension will be artificially high. Since Morgan and Scarlett's data appear to be high, the foregoing discussion is offered as a possible explanation.

A comparison* of the surface tensions of acetone-water solutions at $15^{\circ} \mathrm{C}$. with 
those reported by Traube (13) shows that the latter's data are an average of $0.6 \%$ higher than those reported here. Two factors may contribute to this difference. Probably the concentrations Traube reports are slightly in error, because of his failure to use anhydrous acetone. The density of the material he started with is not reported and thus the water content cannot be estimated by the method described previously (11). The presence of only a trace quantity of water in the starting acetone would make his reported compositions high. Correction of this effect would bring his data into better agreement with those reported here. Considering the refinements in technique which have occurred since 1891 , the agreement of the Traube data is excellent.

\section{ACKNOWLEDGMENT}

This work was carried out in connection with Research Project 1, Tray Efficiencies in Distillation Columns, sponsored by the American Institute of Chemical Lngineers. The authors gratefully acknowledge the support and eacouragement of the A.I.Ch.E. Researeh Committee during the course of this investigation.

They are also indebted to D. E. Sampeon of the University of North Carolina for the construction of the apparatus and to $D$. G. Bethune, Department of Chemical Engineering, North Caroline State College, for the benzene analyses.

\section{LITERATURE CITED}

1. Brunjes, A. S., and M. J. P. Bogart, Ind. Eng. Chem., 35, 258 (1948),

2. Harkins, W. D., "Teehnique of Organic Chemistry," (A. Weissberger, ed.), vol. I, Part 1, 2 ed., p. 366, Interscience Publishers, lnc., New York (1949).

3. Ibid., p. 368.

4. Ibid., p. 374

5. (a) Harkins, W. D., "Physical Chemistry of Surface Films," p. 79,
Reinhold Publishing Corporation, New York (1949).

(b) Reference 2, p. 369.

6. - and F. E. Brown, J. Am. Chem. Soc, 41, 499 (1919).

7. Harkins, H. N., and W. D. Harkins, J. Clin. Investigations, 7, 263 (1929).

8. Morgan, J. L. K., and A. J. Scarlett, Jr., J. Am. Chem. Soc., 39, 2275 (1917).

9. Perry, J. H., "Chemical Enginecrs' Handbook," 3 ed., p. 175, McGraw-Hill Book Compány, Inc., New York (1950).

10. Richards, T. W., and E. K. Carver, J. Am. Chem. Soc., 43, 827 (1921).

11. Thomas, K. T., and R. A. MeAllister, A.I.Ch.E. Journal, 3, 161. (1947).

12. Timmermans, $J_{\text {, "Physico-Chemical }}$ Constants of Pure Organic Compounds," p. 147, Elsevier Publishing Company, New York (1950).

13. Traube, J., Ann. Chem. Justus Liebigs, 265, 27 (1891).

14. Young, T. F, and W. D. Harkins, in "International Critical Tables," vol. IV, p. 467, MnGraw-Hill Book Company, Ine., New York (1928). 


A.I.Ch.E. JOURNAL is published by the American Institute of Chemical Engineers. Editorial Offices are at 25 West 45th Street, New York 36, New York. Annual subscription: nonmember $\$ 9,00$, member $\$ 4.50$; two years, nonmember $\$ 15.00$, member $\$ 7.50$. Additional yearly postage, Canada \$0.50, Pan American Union \$1.50, other foreign \$.00. Foreign subscriptions payable in advance. 

